\title{
E1 Partido Socialista y las huelgas: una relación incómoda. Un análisis de las posiciones partidarias en los primeros años del siglo $\mathrm{XX}$
}

\author{
Lucas Poy \\ IIGG - UBA - Conicet \\ lucaspoy@gmail.com
}

En noviembre de 1902, en el marco de un ciclo de conflictividad obrera que ya se venía extendiendo por más de un año, la Argentina se vio conmovida por la primera huelga general de su historia. ${ }^{1}$ La medida de fuerza, convocada por la Federación Obrera Argentina, de reciente fundación, produjo un enorme impacto en la opinión pública y en los círculos dirigentes del Estado, a punto tal que, en tan solo veinticuatro horas, ambas cámaras del Congreso sancionaron con celeridad la ley 4.144, llamada "de Residencia", poniendo así de relieve la importancia que había alcanzado la "cuestión obrera" en el país. Pocos días después de concluida la huelga, el periódico del Partido Socialista trazaba sin embargo un balance definitivamente sombrío acerca de esta demostración de fuerza de la clase trabajadora local. Los socialistas, en efecto, concluian que "la tentativa de huelga general" había sido una "obra descabellada y absurda que no encuentra otra atenuación que la conducta también descabellada y absurda del Gobierno en los recientes sucesos". En un número especial, editado bajo el estado de sitio, La Vanguardia reivindicaba "la actitud serena, resuelta y sensata del Partido Socialista", en medio "del espantoso caos de los últimos días, creado por la actitud inepta del gobierno y la fantasía revolucionaria de los anarquistas". Frente al "febril y atropellado desconcierto del gobierno" y la "calentura roja de los fanáticos de la violencia”, el Partido Socialista había aplicado "una oportuna ducha de buen sentido", que le habia granjeado simpatias, "al revelarse como partido de pensamiento, de orden y de progreso". ${ }^{2}$

1. El presente trabajo es parte de una investigación posdoctoral sobre la historia del Partido Socialista argentino en la etapa anterior a 1930, que cuenta con financiación del Conicet y de la Fundación Slicher van Bath-de Jong establecida en el CEDLA (Ámsterdam).

2. "El estado de sitio y el Partido Socialista", La Vanguardia, año IX, suplemento al $\mathrm{n}^{\circ} 47,29$ de noviembre de 1902 .

(Archivos, año III, $\mathrm{n}^{\circ}$ 6, pp. 31-51) 
La huelga de 1902 ha quedado grabada, desde entonces, en la historia del movimiento obrero local, y no han faltado los trabajos que se dedicaron a abordarla en la historiografia, particularmente desde el ángulo de su impacto en el desarrollo del anarquismo. Sabemos menos, sin embargo, acerca del modo en que los socialistas argentinos caracterizaron el episodio en el contexto de la interpretación que ya venían realizando, desde una década atrás, acerca del lugar de las huelgas en su estrategia política. La cuestión del vínculo entre acción politica y lucha económica, en efecto, siempre constituyó un clivaje crítico para el PS, una formación cuya composición social echaba fuertes raíces en la clase trabajadora y que influía, de diversas maneras, en numerosas sociedades gremiales. El objetivo del presente artículo es analizar las posiciones del socialismo local con respecto a la cuestión de las huelgas en el agitado período de conflictividad obrera que se extendió entre 1900 y 1902, trazando primero una recapitulación acerca del modo en que el tema había sido abordado en los años inmediatamente anteriores. Como veremos, en el contexto de fuerte agitación que se vivió en esos años, que coincidieron además con la constitución de la Federación Obrera Argentina y culminaron con la declaración de la primera huelga general, el PS fue consolidando sus críticas respecto de la utilidad de las huelgas y, sobre todo, desenvolvió un cuestionamiento a la idea de huelga general. La cuestión, como intentaremos mostrar a continuación, estaba siendo debatida en el movimiento socialista a nivel internacional: en ese sentido el PS argentino desarrollaba una posición que en gran medida coincidia con la de sus contrapartes socialdemócratas de otros países. Nuestra hipótesis es que, si la huelga "grande" de 1896 contribuyó a que surgieran con firmeza las primeras posiciones contrarias a la generalización de las huelgas, la agitación de 1901-1902, en el contexto de una dura disputa con los anarquistas, consolidó aún más esta posición, inscribiéndola ya en forma definitiva entre las líneas medulares de la interpelación del partido.

\section{Antecedentes: los primeros pasos del socialismo y su vinculo con la actividad huelguística (1889-1900)}

Desde sus más tempranos orígenes los socialistas de Argentina se vincularon con las acciones huelguísticas de la clase trabajadora local. De hecho, la intervención en la conflictividad obrera fue lo que permitió a los primeros núcleos socialdemócratas de Buenos Aires dar un primer salto organizativo y político a fines de la década de 1880 . Tal como había señalado Ricardo Falcón (2011) y desarrollamos extensamente en otro trabajo (Poy, 2014), en efecto, el importante ciclo de agitación obrera que atravesó a la ciudad de Buenos Aires en los años 1888 y 
1889 mostró una importante intervención del Verein Vorwärts, el primer núcleo socialista del país, que habia sido fundado en 1882 por emigrados socialdemócratas alemanes y que en el marco del ascenso obrero de fines de esa década logró expandir su influencia más allá del estrecho grupo inicial.

Fue en el marco del ciclo de huelgas de 1888 y 1889 , por otra parte, cuando los socialistas debieron enfrentar el primer ataque abierto por parte de la prensa comercial, que atribuía la existencia de huelgas a la acción de "cabecillas extranjeros", y en particular a los propios militantes socialistas nucleados en el Verein Vorwärts. Fue en este cuadro cuando los socialistas de Argentina desenvolvieron por primera vez una posición respecto de las huelgas, saliendo al cruce de las acusaciones. El Vorwärts respondió que las causas de la agitación, en realidad, debían buscarse en el agudo proceso inflacionario que atravesaba el país en el periodo y caracterizaba a las huelgas "como un mal necesario, como un producto de las circunstancias sociales actuales": las mismas eran inevitables en el capitalismo, en tanto representaban "a menudo el único medio de los trabajadores para defenderse de una excesiva opresión por parte del capital". Las huelgas existían más allá de la voluntad de los socialistas, que no tenían como tarea provocarlas e incluso a menudo las habian "desaconsejado". ${ }^{3}$

El período de edición de El Obrero - el primer periódico socialista en español, publicado desde fines de 1890 hasta fines de 1892- coincidió con una etapa de retracción de la actividad huelguística, y es por ello que la cuestión de las huelgas no ocupó un lugar destacado en sus páginas. En el contexto de una huelga de zapateros, en la primavera de 1892, volvemos a encontrar una reflexión de los socialistas sobre el problema de las huelgas, nuevamente en las páginas del Vorwärts. Otra vez, encontramos una valoración ambivalente: los socialistas alemanes aclaraban entonces que sentian "toda la simpatía hacia los huelguistas", pero que debian caracterizar a la huelga como "precipitada e irreflexiva". De todas formas, los socialistas alemanes caracterizaban que aun si la huelga concluyera con un fracaso - como de hecho ocurrió- no "carecería de utilidad", en tanto sería una "advertencia para los patrones" y para los propios obreros, que en el futuro serian "más sagaces gracias a la experiencia hecha ahora". ${ }^{4}$

A partir de la aparición de La Vanguardia, en 1894, la actividad de los socialistas entró en una nueva etapa, marcada por la creciente articulación de los diferentes grupos y una serie de avances organizativos y políticos. La postura de los socialistas respecto de la huelgas, en este

3. "Die Streiks und die Sozialisten", Vorwärts, n 100, 17 de noviembre de 1888.

4. "Zum Streik der Schuhmacher", Vorwärts, n 307, 19 de noviembre de 1892. 
período, debe ponerse en relación con su caracterización sobre la madurez de las condiciones para desarrollar un agrupamiento propiamente socialista en el país, uno de los puntos fundamentales de debate en esta etapa. La Vanguardia argumentaba sistemáticamente que el avance del desarrollo capitalista en Argentina habia cerrado las posibilidades de ascenso social para los trabajadores, y por ello explicaba el desarrollo de las huelgas, que eran justas e inevitables, así como la expansión de las sociedades gremiales.

Vemos cómo iban definiéndose, en fecha tan temprana como mediados de la década de 1890, una serie de caracterizaciones que constituirian el núcleo de la postura socialista sobre las huelgas. Si, por un lado, éstas eran un producto inevitable del desarrollo capitalista, y debían ser no solo defendidas de los ataques patronales sino incluso reivindicadas como un sintoma del avance de una delimitación clasista por parte de los trabajadores, constituian al mismo tiempo, por otro lado, un método "atrasado" de la lucha de clases. Mientras las huelgas podrian traer como resultado mejoras transitorias, siempre y cuando fueran impulsadas "en el momento propicio e inteligentemente dirigidas", la acción política era el camino que permitía alcanzar "poco a poco reformas de un orden más radical y permanente que les acercan al día tan anhelado de su emancipación económica". ${ }^{5}$ La superioridad de la "acción política" se veía reforzada por el hecho de que permitia consolidar la unidad de conjunto de la clase obrera: mientras las eventuales mejoras de una huelga solo eran aprovechadas por el gremio que las realizaba, las obtenidas en el terreno político favorecian "a la clase obrera en general". ${ }^{6}$

A mediados de 1896, una generalizada agitación huelguística conocida como "huelga grande" llevó al conflicto a decenas de gremios de la ciudad de Buenos Aires y otros puntos del país. En el caso de los socialistas, que jugaron un papel destacado en la organización de muchos de esos conflictos - particularmente el de los trabajadores de los talleres ferroviarios - la experiencia de la huelga marcó decisivamente sus planteos y posicionamientos. La caracterización que ya habian elaborado sobre las huelgas implicó una cerrada negativa a extender el conflicto a otros oficios, en tanto consideraban que la generalización de la huelga en todos los gremios no contribuiría a asegurar la victoria sino que, al contrario, era un mecanismo incapaz de proveer a un triunfo de las reivindicaciones obreras y proclive a favorecer los planteamientos anarquistas. La larga extensión del conflicto y su culminación con una derrota, por otra parte, contribuyó a reforzar dicha postura.

5. "Huelgas y acción política", La Vanguardia, año II, n 2, 12 de enero de 1895.

6. "Las huelgas son una forma atrasada de la lucha de clases. El voto es la gran arma del trabajador", La Vanguardia, año II, n 51, 21 de diciembre de 1895. 
Cuando se acercaba el cierre del conflicto, Juan B. Justo trazó un balance que resumía los posicionamientos desarrollados por el socialismo local en este período temprano. Desde su perspectiva, las huelgas eran el primer paso en la lucha del proletariado: aun cuando fracasaran, eran "en principio buenas para la clase obrera", en la medida en que sacaban a los trabajadores de la pasividad o la inacción y contribuían a fortalecer "los sentimientos y hábitos de solidaridad" y a experimentar cómo el gobierno se ponía "servilmente al servicio de los patrones". La huelga, sin embargo, era también para Justo "una forma de lucha rudimentaria". En su argumentación agregaba la idea de que constituía en realidad una "acción negativa y pasiva", porque en un conflicto huelguístico los trabajadores se reunian "para no hacer". La lucha política - y, agregaba Justo, la asociación cooperativa- eran por el contrario un "esfuerzo activo", a través del cual los trabajadores estarian en condiciones de adquirir "los conocimientos y la disciplina que les hacen falta para llegar a su emancipación". ${ }^{7}$

Luego de la derrota de la "huelga grande" se abrió un período de pronunciada retracción de las luchas obreras, que se extendió durante varios años. El reflujo de la actividad huelguística, por otra parte, coincidía con una etapa de crisis económica, una de cuyas consecuencias fue el incremento de la desocupación. Las dificultades eran bien claras para los propios militantes activos en el periodo: en un número especial editado el $1^{\circ}$ de mayo de 1908, por ejemplo, cuando La Vanguardia repasaba los principales episodios de la lucha de clases de las dos décadas previas, refería que "el fracaso" de la huelga de 1896 había traído "aparejado un decaimiento casi completo, y con él la desaparición de las sociedades gremiales que tuvieron mal éxito en sus huelgas". Según el periódico socialista, 1897 habia estado marcado por "una escasez de trabajo bastante importante" y 1898 no habia modificado las cosas: siendo un "año de escasez de trabajo, el número de huelgas fue reducido y de importancia secundaria". ${ }^{8}$

Las cosas empezaron a modificarse, y solo parcialmente, en 1899, mientras que en 1900 la cantidad de huelgas se incrementó casi cuatro veces. La agitación obrera, de todos modos, conocería un salto decisivo en 1901 y, sobre todo, en 1902, un bienio en el que se desenvolvió un nuevo ciclo de ascenso de la conflictividad, más importante aún que los anteriores de 1888-1890 y 1894-1896 (Oved, 1978: 132; Marotta, 1960: 134; Korzeniewicz, 1989). La precariedad de las condiciones de vida de los trabajadores y los primeros síntomas de un nuevo ciclo de agitación social, por otra parte, contribuían a poner en primer plano

7. "La acción obrera", La Vanguardia, año III, n 40, 3 de octubre de 1896.

8. La Vanguardia, 1 de mayo de 1908. 
la llamada "cuestión social". Todavía en agosto de 1901 se realizó un meeting de desocupados, que provocó una gran impresión y llevó a que el diario La Prensa lanzara su conocida serie "Los obreros y el trabajo", durante agosto, septiembre y octubre.

En este cuadro, y acicateado por una reactivación económica que ya estaba tomando fuerza, en la segunda mitad de 1901 comenzó un ascenso obrero en toda la línea, con huelgas de importancia. A diferencia de lo ocurrido en los años anteriores, éstas tendrán ahora un alcance nacional. En agosto se produjo una huelga de los trabajadores que tendian la vía férrea de Bahía Blanca a Olavarría, que culminó con un triunfo de los huelguistas. En octubre tuvo lugar un agudo conflicto en la Refinería Argentina de Rosario, cuando un millar de trabajadores se declararon en huelga reclamando aumento de salario y disminución de la jornada laboral. En el marco de la represión policial contra una asamblea de huelguistas, cayó el primer muerto del movimiento obrero argentino, el joven Cosme Budislavich, el 20 de octubre de 1901.

A caballo del siglo, en suma, el movimiento obrero argentino desenvolvia una predisposición de lucha que implicaba una fuerte tendencia a la generalización de las huelgas. Tal como había ocurrido en los dos procesos de ascenso huelguístico de la década anterior, la aceleración de la agitación obrera dio lugar a un reanimamiento de la actividad de las sociedades gremiales y empujó a la acción conjunta de las diferentes sociedades de resistencia, poniendo a la orden del día la cuestión de construir una federación de gremios. La acción conjunta entre diversas sociedades de oficios se vio precedida por la aparición de un periódico, llamado La Organización y editado por un conjunto de sociedades gremiales, cuyo primer número vio la luz el 10 de enero de 1901. Poco después, en el mes de febrero, la sociedad de mecánicos lanzó la iniciativa de avanzar en la constitución de una federación. Con la presencia de unos 50 delegados en representación de 27 sociedades, un congreso reunido el 25 de mayo de 1901 constituyó la Federación Obrera Argentina (FOA). Tal como ha sido analizado por la historiografia, se trató de una iniciativa que contó con la participación tanto de militantes socialistas como anarquistas y su mérito histórico fue el de dejar conformada una federación obrera que ya no perdería continuidad. ${ }^{9}$

Tanto los anarquistas como los socialistas, en efecto, valoraban positivamente la iniciativa unitaria. La Protesta Humana, el principal órgano de prensa de los anarquistas de orientación organizadora, llamaba a apoyar la iniciativa de la federación, "buena para luchar con ventaja contra la burguesía", y recomendaba a los militantes libertarios de las diferentes sociedades gremiales que supieran "ilustrar las sesiones del

9. Sobre el congreso, ver Abad de Santillán (1933), Marotta (1960) y Oved (1978). 
congreso con criterio bien orientado". ${ }^{10}$ Por su parte, los socialistas valoraron la iniciativa, considerando que este avance venía "después de un largo período de estancamiento" y que ahora se notaba "una sensible agitación en varios gremios". ${ }^{11}$ De todos modos, la incomodidad ante una organización que estaba lejos de quedar bajo control de los socialistas no dejaba de expresarse: se dejaba claro que, debido al "elemento heterogéneo que componía" el congreso, solo había podido tener lugar "una fusión amistosa entre las dos tendencias allí representadas". Esta fusión había permitido "acertados acuerdos" pero al mismo tiempo había contribuido a que "se aceptasen conclusiones contradictorias impuestas por una imprevisión de los delegados". ${ }^{12}$

En los meses siguientes, con la Federación recién constituida, estas tensiones irian agudizándose, en el contexto de un incremento de la conflictividad obrera. En realidad, aunque socialistas y anarquistas coincidian en impulsar la Federación, lo hacían con perspectivas distintas, que se vinculaban directamente con la posición elaborada ante la cuestión de las huelgas, y en particular la cuestión de la huelga general. Mientras los anarquistas veían a la federación como un paso fundamental para impulsar esta última, los socialistas la entendian como una posible herramienta capaz de evitar estallidos huelguísticos generalizados de consecuencias negativas para el movimiento obrero.

\section{La cuestión de la huelga general: el debate nacional e internacional}

A lo largo de 1901 y 1902, en efecto, encontramos en la prensa socialista argentina una constante referencia a la cuestión de la huelga general, con el objetivo de dejar sentada una delimitación con los anarquistas. Ya en un editorial publicado a comienzos de 1901, el dirigente socialista Ángel Sesma, por entonces miembro del comité ejecutivo, planteaba que no tenía sentido "romper lanzas sobre si se llegará o no se llegará a la huelga general, sobre si será buena o sobre si será mala", debido a que no estaban dadas las condiciones para la misma. En realidad, hablar de huelga general era "un absurdo" y tratar de llevarla a cabo era "beneficioso solamente para la clase capitalista". Sesma planteaba que "a la huelga general futura anteponemos la organización

10. "Congreso obrero", La Protesta Humana, 23 de marzo de 1901, citado en Oved (1978: 134). Los anarquistas de orientación anti-organizadora, ya más débiles en este período, se manifestaron en contra de la federación.

11. Guido Anatolio Cartey, "Federación gremial", La Vanguardia, año VIII, nº 8, 23 de febrero de 1901.

12. "El congreso corporativo", La Vanguardia, año VIII, n 23, 8 de junio de 1901. 
del presente, de esa especie de andamiaje, de esa especie de gimnasia, necesaria para preservar a los trabajadores de los fatales accidentes de la lucha, y sobre todo para adiestrarlos a la lucha misma". ${ }^{13}$ Poco más tarde, en el cuarto congreso del partido, reunido en julio de 1901 en La Plata, se aprobó una escueta resolución de compromiso sobre el tema, que establecía que el PS reconocia "la importancia de la huelga general y acepta los criterios vertidos al respecto por los Congresos Socialistas internacionales" (Partido Socialista Argentino, 1910: 126).

Es que, en efecto, el debate sobre la huelga general ocupaba un lugar fundamental en las discusiones que atravesaban al anarquismo y al socialismo a nivel internacional. Aun antes de la gran discusión sobre la huelga general política, puesta en primer plano en la primera década del siglo al calor del impacto de la revolución rusa, ${ }^{14}$ la cuestión ya había sido objeto de debates y posicionamientos por parte de los marxistas. Ya en la década de 1870 Engels había planteado una posición critica frente a una táctica que se consideraba propia del anarquismo:

Los acontecimientos políticos y los abusos de las clases gobernantes facilitarán la emancipación de los obreros mucho antes de que el proletariado llegue a reunir esa organización ideal y ese gigantesco fondo de reserva. Pero, si dispusiese de ambas cosas, no necesitaría dar el rodeo de la huelga general para llegar a la meta (1873).

Esta posición fundamental habia marcado fuertemente los posicionamientos de los militantes socialistas, si bien desde la fundación de la Internacional, en 1889, el tema volvió a aparecer en el debate de manera recurrente. Una proposición del holandés Domela Nieuwenhuis (1846-1919), en favor de la huelga general, había sido rechazada ya en el congreso de Zurich, en 1893 (Joll, 1966: 133). El congreso de Londres, celebrado en 1896, aprobó una resolución que abordaba la cuestión del vínculo entre luchas económicas y acción política. Sus términos permiten contextualizar los posicionamientos del PS argentino, analizados más arriba, y ponen de manifiesto que los socialistas locales desenvolvian una interpretación que se encontraba en sintonía con las resoluciones de la socialdemocracia internacional:

La lucha sindical de los trabajadores es indispensable para resistir la tiranía económica del capital, y por lo tanto mejorar

13. Ángel Sesma, "La huelga general. Otra vez", La Vanguardia, año VIII, n 3, 2 de febrero de 1901.

14. Se trata de un tema que excede cronológicamente el alcance de este artículo y que no abordamos aquí. Ver, al respecto, Aricó (1978). 
su situación actual. [...] La lucha económica reclama también la acción política de la clase trabajadora. Lo que sea que obtengan los trabajadores de los patrones en disputas abiertas debe ser confirmado por la ley para poder ser conservado, mientras que los conflictos sindicales pueden en otros casos ser innecesarios debido a medidas legislativas. (Histoire, 1980a: 384)

A partir de estas consideraciones, la resolución del congreso de Londres planteaba que

las huelgas y los boicots son medios necesarios para llevar adelante los objetivos de los sindicatos. Lo que es inmediatamente necesario es la organización completa de las clases obreras, ya que el manejo exitoso de una huelga depende de la fuerza de su organización. (Histoire, 1980a: 385)

En las actas oficiales del congreso de Londres, editadas en inglés, no figura sin embargo una frase incluida en el medio de dicho párrafo. En efecto, tal como se puede comprobar leyendo la versión alemana, la formulación completa de la primera frase era: "El congreso de Londres considera que las huelgas y los boicots son medios necesarios para llevar adelante los objetivos de los sindicatos, pero no ve la posibilidad actual de una huelga general internacional' (cursivas nuestras). ${ }^{15}$ Ocurre que también habia existido una resolución de minoria, impulsada por militantes sindicales franceses, que llamaba explícitamente a considerar la cuestión de la huelga general (Histoire, 1980a: 386).

El tema fue objeto de un debate específico en el siguiente congreso de la Internacional, celebrado en París en septiembre de 1900, donde nuevamente la comisión encargada de debatir la cuestión quedó dividida. Por la posición mayoritaria, apoyada por los socialistas alemanes y austríacos, informó el alemán Carl Legien (1861-1920), líder de la poderosa ala sindical del partido. Según las actas del congreso, Legien argumentó que la huelga general no era "discutible actualmente". Lo que estaba planteado, en realidad, era continuar fortaleciendo la organización sindical: "Para salir a la batalla", argumentó, "hace falta comenzar por formar grandes batallones; hacen falta numerosos y

15. "Der kongress hält den Streik und Boykott für ein notwendiges Mittel zur Erreichung der Aufgaben der Gewerkschaften, sieht aber die Möglichkeit für einen internationalen Generalstreik nicht gegeben" (Histoire, 1980a: 489). No se publicaron actas oficiales en francés (Haupt, 1965: 157). Hamon (1896) destacó en su trabajo la notoria omisión de tan importante frase en la versión inglesa: "Los autores de esta falsificación querían para los socialistas del continente afirmar la imposibilidad de la huelga general y la no imposibilidad para las trade unions inglesas" (1896: 277). 
pujantes sindicatos" (Histoire, 1980b: 130). Para Legien, mientras el proletariado no contase "con sindicatos numerosos y fuertemente organizados, declarar la huelga general no sería deseable más que para la burguesía, porque esta huelga general solo tendría una consecuencia: dejar indefenso al proletariado, que será fusilado o vencido por hambre". Partiendo de estas consideraciones, la propuesta de resolución de mayoría se limitaba a "ratificar la resolución votada en el congreso internacional de Londres en 1896, que trata de la huelga general" (idem: 358).

La posición minoritaria fue defendida por el francés Aristide Briand (1862-1932), un dirigente socialista que pasaria de sostener posiciones combativas al interior del movimiento sindical a convertirse luego en un hombre de estado del régimen burgués, llegando a ser varias veces primer ministro de su país. Briand se preguntaba cómo era posible "rechazar la idea de huelga general sin poner en duda, por esta misma negación, la eficacia de la organización sindical en su conjunto". Para Briand, la huelga general era "el estimulante más activo de la organización sindical"; consideraba, además, que veía a la huelga general "como el modo más eficaz de llevar a cabo la revolución" (Histoire, 1980b: 130-132). En consonancia con estos planteos, la propuesta de resolución de minoria invitaba "a los trabajadores del mundo entero a organizarse para la huelga general, sea que esta organización constituya en sus manos en simple medio de presión (...) o sea que, cuando las circunstancias se muestren propicias, esta se ponga al servicio de la revolución social" (idem: 133-134).

La moción mayoritaria obtuvo un amplio triunfo en la sesión plenaria, resultando aprobada por 27 votos a 7 . A pesar de que, llamativamente, el voto argentino - por representación, a través del francés Achille Cambier - en el congreso de París refrendó la postura de Briand, los posicionamientos elaborados por La Vanguardia y por la dirección del PS argentino se colocaban inequívocamente en la línea de la postura mayoritaria de la Internacional. Ya hemos visto cómo Sesma había argumentado en términos similares a los utilizados por Legien en Londres, pero es posible encontrar más ejemplos. El 19 de octubre de 1901, por caso, se publicó en La Vanguardia un artículo de El Socialista de Madrid, con el título de "La huelga general favorece a los patronos". Se sostenía alli que las huelgas generales provocaban un desgaste que llevaban a la derrota de los trabajadores planteando, incluso, que eran los patrones quienes buscaban convertir en generales las huelgas parciales iniciadas en algún oficio, para cortar de recursos a los trabajadores en conflicto y obligar a los trabajadores a "rendirse por hambre". Según El Socialista, la táctica de los anarquistas partidarios 
de la huelga general coincidía con la de los capitalistas en el plano de la búsqueda de hacerla "violenta". ${ }^{16}$

Este alineamiento del PS argentino con la postura dominante a nivel internacional puede volver a encontrarse un año más tarde, en junio y julio de 1902, cuando La Vanguardia publicó por entregas el trabajo "Socialismo y anarquismo. Consideraciones sobre una y otra escuela”, del valenciano Rafael Carratalá Ramos (1859-1909). En su sexto capitulo, dedicado a la huelga general, el socialista español citaba a Gabriel Deville, quien caracterizaba a la huelga general como un "plan descabellado [que] debe ser desechado por todos los obreros conscientes de los hechos y de sus consecuencias, por todos los que razonan sin preocupación y no se contentan con palabras". Para Carratalá, se corría el grave riesgo de una derrota que sería "desastrosa para la causa del trabajo y del progreso". ${ }^{17}$ En esa línea, en el mismo número de La Vanguardia, otro artículo caracterizaba que "en algunos puntos donde los obreros aún viven en una gran confusión de ideas", la huelga general y la revuelta eran "los medios predilectos que emplean frecuentemente con el fin de realizar algunos sueños de sociedad futura que les sugieren ciertos profetas, pero hasta ahora lo único que han conseguido ha sido empeorar más la situación". ${ }^{18}$

En suma, el Partido Socialista argentino llegaba al período de fuerte conflictividad obrera de fines de 1902 con una postura elaborada en torno a la cuestión de las huelgas que se insertaba en el marco más general de los posicionamientos desenvueltos internacionalmente por la socialdemocracia de la época. Las huelgas impulsadas y recomendadas por los socialistas eran siempre huelgas parciales, promovidas por sociedades sólidamente estructuradas, capaces de afrontar la resistencia a los patrones. Eran huelgas no violentas, que debian sostenerse por la unidad y la conciencia de los trabajadores al ausentarse del trabajo hasta quebrar la resistencia de los patrones, por la via de una negociación o un arbitraje si era necesario, que permitiera mejorar en algo las condiciones de vida y trabajo. Eran huelgas, sobre todo, que debían servir para fortalecer las organizaciones sindicales y estimular una conciencia de clase cuya máxima expresión era la incorporación de los trabajadores a las filas socialistas y la intervención decisiva en la vida política.

16. "La huelga general favorece a los patrones", La Vanguardia, año VIII, n 42,19 de octubre de 1901.

17. Rafael Carratalá Ramos, "Socialismo y anarquismo. Consideraciones sobre una y otra escuela. VI. La huelga general”, La Vanguardia, año IX, nº 28, 12 de julio de 1902. 18. Jorge Linstein, "Medios de lucha”, La Vanguardia, año IX, $\mathrm{n}^{\circ} 28,12$ de julio de 1902. 
Los acontecimientos en Argentina, sin embargo, iban a desenvolverse en otra dirección. Los primeros meses de 1902 estuvieron marcados por una aceleración de las tensiones: en enero, nuevamente el centro de atención se ubicó en Rosario, donde se desarrolló otra huelga general. Dicha ciudad, precisamente un centro obrero donde la influencia anarquista era muy superior a la socialista, aparecía como el ejemplo del peligroso camino al que llevaba la generalización de los conflictos. El comité ejecutivo del partido realizó entonces un balance muy negativo de lo ocurrido. La huelga general había resultado "un conato desgraciado, pues además de no haber participado en ese movimiento sino una escasa minoria, fue un fracaso, dejando como consecuencia varias víctimas, un profundo desaliento en las filas obreras y el fracaso de los estibadores". ${ }^{19}$

Fue en este contexto en el que se procesaria la ruptura de la Federación Obrera, cuando aún no se había cumplido un año de su fundación. Las tensiones se hicieron evidentes a comienzos de 1902, cuando varias sociedades gremiales influidas por militantes socialistas decidieron crear una "Unión General de Trabajadores", haciéndose fuertes además en el control de la publicación del periódico La Organización. En un primer momento, la dirección del partido y la redacción del periódico socialista vieron con ojos críticos la creación de la UGT: el 8 de febrero de 1902, por ejemplo, el editorial de La Vanguardia estaba dedicado a criticar la reciente formación de la nueva organización, que era considerada "una aberración, explicable solo cuando se considera que el sectarismo suele primar sobre los bien entendidos intereses de clase". ${ }^{20}$ Sin embargo, cuando en abril de 1902 se produjo la ruptura, el periódico socialista realizó una valoración positiva. Enrique Dickmann caracterizaba lo ocurrido como inevitable, y por lo tanto positivo: "Nadie ha de lamentar lo sucedido, aunque a primera vista parece lamentable. Más bien han de felicitarse por un desenlace que servirá de provechosa lección a los obreros conscientes, de fecunda enseñanza a los gremios serios y bien organizados".

19. "A los trabajadores de la República Argentina”, La Vanguardia, año IX, n 3,18 de enero de 1902. Si Rosario era la "Barcelona argentina", según una definición de Enrique Dickmann que hacía referencia a la influencia anarquista en dicho puerto del Litoral, apenas unas semanas más tarde estallaba una dramática huelga general precisamente en la capital catalana, que conmovió a toda España y dejó centenares de muertos (Colodrón, 1971; Duarte, 1991). El editorial de La Vanguardia del 22 de febrero estaba dedicado al episodio, que era visto en un prisma fuertemente negativo, culpando nuevamente a los anarquistas por lo acontecido ("Barcelona", La Vanguardia, año IX, $n^{\circ} 8,22$ de febrero de 1902).

20. "La Federación Obrera Gremial Argentina", La Vanguardia, año IX, nº 6, 8 de febrero de 1902. 
De nuevo, encontramos que detrás de la discusión sobre la federación de gremios la cuestión clave era la postura acerca del rol de las huelgas: para los socialistas, se había puesto de manifiesto que unos y otros veían a la federación como un medio para alcanzar fines bien distintos. Los anarquistas querian "celebrar un congreso para tratar del 'sabotaje', de la 'revolución social', de la 'huelga general' y de la inutilidad del 'arbitraje'; pero no tienen el valor moral de afrontar las responsabilidades propias". Por eso habian tramado "un subterfugio ingenioso" y fraguado, según los socialistas, las representaciones del congreso. El periódico socialista recomendaba a los gremios que se habian retirado "celebrar otro congreso genuinamente obrero, donde se tratarán sus intereses económicos con un criterio culto y elevado". Dickmann planteaba que, "frente a la Federación anarquista, los gremios conscientes han de fundar la 'Unión general de los trabajadores', y han de cuidarse muy bien de no caer otra vez en la trampa preparada por los procuradores y aves negras de la anarquía". ${ }^{21}$

\section{La huelga general de noviembre de 1902 y la sanción de la Ley de Residencia}

Todo este recorrido llegaría a un desenlace a fines de 1902, cuando se produjo la primera huelga general de la historia del país. La conflictividad seguía mostrando un fuerte ascenso desde los meses anteriores: en forma paralela a la ya mencionada huelga general de Rosario había estallado en enero un agudo conflicto en el puerto de Buenos Aires y la agitación continuó durante los meses posteriores, destacándose las huelgas de cocheros y de panaderos en la capital (Oved, 1978: 206). En el transcurso del año, por otra parte, se había avanzado en la conformación de sindicatos que nucleaban a los trabajadores del mismo oficio en distintos puntos del país, generalmente bajo fuerte influencia anarquista, lo cual sería un factor de impulso para la generalización de las huelgas. ${ }^{22}$

Los acontecimientos que llevaron a la huelga general son conocidos: el conflicto comenzó con el reclamo de los estibadores para reducir el peso de las bolsas de cereales, al que luego se sumaron los obreros de los depósitos del Mercado Central de Frutos. Ante el rechazo de los patrones a las exigencias de los obreros del MCF, la Federación de Estibadores convocó a una huelga solidaria, y lo mismo hizo la Federación

21. Enrique Dickmann, "El congreso gremial", La Vanguardia, año IX, n 17, 26 de abril de 1902 .

22. Se destacan fundamentalmente la Federación del Rodado y la de Estibadores. Ver Darraidou (2011: 96-97). 
de Rodados, paralizando así el transporte y la actividad del puerto. Ante los rumores de que el gobierno se aprestaba a sancionar una legislación represiva, como efectivamente sucedió, el 20 de noviembre la FOA decretó la huelga general. ${ }^{23}$

El desencadenamiento de conflictos generalizados y la velocidad del gobierno para responder con la Ley de Residencia parecian confirmar los peores temores de los socialistas. En la edición del 15 de noviembre apenas aparecen referencias a la huelga ya iniciada por los estibadores, pero una semana más tarde la aceleración de los acontecimientos ya había cambiado la situación. El sábado 22 de noviembre, La Vanguardia estaba encabezada por un editorial titulado "A la acción, compañeros". La línea fundamental de la caracterización de los socialistas era que se trataba de un movimiento no deseado, impulsado por sus adversarios políticos con una orientación que lo llevaría al fracaso, en el cual sin embargo era necesario intervenir para atenuar las consecuencias negativas.

En sintonía con lo que se había argumentado previamente desde un punto de vista teórico y también para los casos de huelgas generales en otros países, ahora se subrayaba el gran peligro que corría el movimiento obrero argentino debido a la irresponsabilidad de los anarquistas. Lo que se observa, en ese primer número de La Vanguardia publicado al calor del conflicto, es que la táctica de los ácratas era vista como causante de la generalización huelguística que estaba en pleno curso, en un número del periódico que estaba mucho más centrado en criticar a sus adversarios políticos que en denunciar la represión gubernamental. Según La Vanguardia, la clase trabajadora estaba siendo conducida "por caminos tortuosos en derechura al desastre inmediato", por responsabilidades de "aquellos que, erigiéndose en apóstoles y redentores, especulan maliciosamente su inconsciencia". ${ }^{24}$ Los anarquistas, "obcecados con su sistema terrorífico, no solo han mirado con desdén toda idea de cálculo y previsión antes de lanzarse a la lucha, sino que, con sus destemplanzas y amenazas, provocan primero en los patrones el espíritu de venganza, y con su irresistible tendencia a extremar el conflicto, generalizando el paro, dan lugar después a los trastornos consiguientes". ${ }^{25}$

La semana siguiente, ya bajo estado de sitio y con la Ley de Residencia sancionada, el Partido Socialista no pudo publicar La Vanguardia con su formato habitual. En su lugar, fue editado el 29 de noviembre un boletín especial, de menor tamaño, con el encabezado "Al pueblo". El principal cambio con respecto a lo publicado previamente es que ahora se dedicaba un espacio mucho mayor a defender a los huelguistas,

23. Ver Oved (1978: 247-277), Marotta (1960: 145-151) y Boido (2002: 168-175).

24. "A la acción, compañeros", La Vanguardia, año IX, n 47, 22 de noviembre de 1902.

25. "Labor estéril", La Vanguardia, año IX, n 47, 22 de noviembre de 1902. 
explicar sus reivindicaciones y atacar a la burguesía y al estado. El manifiesto partía de valorar positivamente la lucha reivindicativa que había iniciado la huelga, caracterizando a los peones de las barracas y el MCF como "un gremio modesto y laborioso" con "reivindicaciones justísimas". A su vez, se caracterizaba positivamente la huelga solidaria declarada por los estibadores y por los carreros, un "acto de inteligente solidaridad [que] habría asegurado el triunfo de los barraqueros", de no haber sido por "nuevas causas de perturbación y de desquicio" que vinieron a "desbandar todo el movimiento". Estas causas se referían, en primer lugar, a los aprestos del gobierno para sancionar una ley represiva. Pero en segundo término, nuevamente, el PS enfocaba su crítica en la actitud de los anarquistas, que "creyendo que iban a poner al gobierno en la necesidad de renunciar a los proyectos bárbaros que acariciaba, lanzaron, con fecha 20 de noviembre, un enérgico manifiesto incitando a la huelga general". ${ }^{26}$

La caracterización de los socialistas, que se veían a sí mismos como los encargados de dotar de "responsabilidad" al movimiento y morigerar las consecuencias negativas de la huelga general, no se limitó a la recomendación a sus militantes de que intervinieran en sus respectivos gremios sino que implicó también la búsqueda de entablar una negociación con el gobierno. Fue en este contexto que el comité ejecutivo del PS, reunido el 22 de noviembre, decidió formar una comisión para entrevistarse con el presidente de la República e intentar abrir una negociación. La iniciativa no prosperó, porque pocas horas después de que el comité ejecutivo tomara estas resoluciones, en la misma noche del 22, el Congreso sancionó la ley de residencia. Aunque el presidente no aceptó reunirse con la comisión, otorgó una audiencia a uno de sus miembros, Celindo Castro, que tampoco tuvo resultados positivos porque a las pocas horas el gobierno decretó el estado de sitio.

En suma, el manifiesto del 29 de noviembre reflejaba la posición de un partido que ponía de relieve su incomodidad ante el rumbo que habian tomado los acontecimientos: de una huelga parcial en reclamo de reivindicaciones justas, apoyada por algunos gremios solidarios, se había pasado a una huelga general que tendría consecuencias muy gravosas. Al poner la responsabilidad tanto en el gobierno como en la dirección anarquista de la Federación obrera, los socialistas volvian a manifestar uno de los rasgos más característicos de su interpretación política: la compartida "ignorancia" de los anarquistas y de la burguesia, que eran incapaces de comprender la dinámica de un progreso histórico que solo los socialistas sabían interpretar. En este marco, no sorprende que la tarea que se atribuyó el partido fuera la de intervenir en el conflicto

26. "Al pueblo", La Vanguardia, suplemento al n 47, 29 de noviembre de 1902. 
para desenvolver una tarea que parece fundamentalmente pedagógica: no solo en las propias filas obreras, para atenuar la influencia de la prédica anarquista, sino incluso en las altas esferas gubernamentales, designando a una comisión para entrevistarse con las máximas autoridades con un propósito de mediación.

Los socialistas debieron sufrir una fuerte represión, al igual que todas las organizaciones obreras. En efecto, numerosos dirigentes y militantes del partido fueron detenidos, los centros socialistas fueron clausurados, se prohibió la publicación de los periódicos y fue saqueado el local de la Sociedad Luz. Una vez sancionada la ley, por otra parte, el Partido Socialista orientó su política en dos direcciones: por un lado, continuó denunciando la responsabilidad conjunta del Estado y de sus adversarios anarquistas por lo ocurrido; por el otro, convocó a los trabajadores a desenvolver una respuesta política ante la fuerte avanzada represiva del gobierno. Ante el desinterés del gobierno por recibir a la comisión socialista, el partido resolvió publicar en los diarios del lunes 24 una serie de declaraciones, en las que establecía su apoyo moral y material a la huelga de los peones del Mercado de Frutos. En segundo lugar, se denunciaba la conducta del gobierno, que había enviado soldados y marineros para reemplazar a los huelguistas, y la "actitud descomedida del presidente", que se había negado a recibir a la delegación socialista, y se condenaba "enérgicamente la ley de residencia". No se privaban, sin embargo, de agregar que el partido "deplora[ba] la actitud asumida por algunos gremios al declararse en huelga por simple espíritu de solidaridad hacia los barraqueros, estibadores y carreros, actitud que fue determinada por la propaganda anarquista y que es contraproducente". ${ }^{27}$

La propuesta de realizar una acción conjunta, de carácter político, en contra de la Ley de Residencia, volvió a poner de manifiesto hasta qué punto las diferencias entre anarquistas y socialistas en torno a la cuestión de la huelga general hacian casi imposible cualquier actividad unificada. El comité ejecutivo del PS envió en esas mismas horas sendas notas a la Federación obrera, dirigida por los anarquistas, y al Comité de Propaganda Gremial, de orientación socialista, con el objetivo de convocar a una manifestación unitaria contra la ley de residencia, el mismo martes 25 de noviembre. Según la nota, la sanción de la ley era "un golpe mortal dado a la organización obrera de este país", ante lo cual era necesario "que todas las fuerzas obreras se aúnen en el propósito común de realizar una formidable manifestación de protesta". Sin embargo, la respuesta de la Federación fue negativa: en nota enviada al comité ejecutivo del PS, la conducción de la FOA señalaba que "el único 
medio de combatir la citada ley de residencia es la huelga general, para la cual invita a todas las sociedades gremiales a adherirse". ${ }^{28}$

\section{Conclusión}

Entre las primeras huelgas que recorrieron la ciudad de Buenos Aires, en el bienio 1888-1889, y el agudo proceso de agitación que llevó a la huelga general de noviembre de 1902 había pasado apenas algo más de una década, pero durante la cual se procesó una muy rica experiencia política para el movimiento obrero argentino. Como hemos visto, los socialistas locales intervinieron en los procesos de conflictividad desde sus mismos orígenes, jugando en ellos un papel activo y desenvolviendo una decidida militancia en favor del triunfo de las huelgas y medidas de fuerza. Las huelgas y las luchas económicas eran correctamente caracterizadas como una consecuencia inevitable del desarrollo capitalista del país y el consecuente proceso de consolidación de su clase obrera. Al mismo tiempo, sin embargo, los socialistas no dejaban de mostrar una notoria incomodidad ante las huelgas: consideraban que se trataba de una forma de lucha de carácter rudimentario, inferior sin dudas a la organizada y disciplinada acción politica que solo un fuerte partido de clase podia encarar para obtener mejoras significativas para la clase trabajadora y desenvolver una lucha por el poder politico y la transformación de la sociedad.

La caracterización de los socialistas sobre las huelgas debe entenderse en el marco de la interpretación más general que trazaban sobre el desarrollo de la sociedad en la que debian desenvolver su actividad y en relación con el fuerte debate político con los anarquistas que atravesaba al movimiento obrero a nivel internacional. Para los socialistas, sus adversarios anarquistas expresaban las tendencias más retrasadas de una clase trabajadora inexperta, y al mismo tiempo las reforzaban, generando estallidos violentos que solo provocaban una reacción de la burguesía y el estado, haciendo así retroceder aún más el desarrollo del proletariado. El argumento de fondo, que se repetía habitualmente en las polémicas entre ambas fuerzas políticas, es que los anarquistas eran incapaces de advertir el desarrollo y las tendencias "evolutivas" de la sociedad y daban a la violencia un lugar que los socialistas rechazaban.

En este artículo hemos intentado mostrar cómo esta caracterización, que resulta constitutiva del socialismo argentino, se consolidó en fechas muy tempranas. Subrayamos también que se trataba de posicionamientos que no eran de ningún modo exclusivos del socialismo argentino, sino que antes bien se insertaban dentro de las caracterizaciones y

28. ídem. 
debates que se desenvolvian al mismo tiempo en la socialdemocracia internacional. Por otra parte, contribuimos a señalar que los diferentes procesos de agitación y movilización obrera del período fueron un factor que contribuyó a reforzar esta perspectiva, dándole cada vez mayor peso dentro de las formulaciones partidarias. El análisis conjunto de los diferentes ciclos de conflictividad obrera y de la historia politica de las izquierdas se revela nuevamente enriquecedor en este sentido: en torno al pico de conflictividad de 1896, en efecto, se procesó por una parte un giro político al interior del anarquismo que dio lugar a la consolidación de la orientación "organizadora" y, al propio tiempo, se reforzó en el socialismo una perspectiva fuertemente crítica de las huelgas. En los años posteriores, esta divergencia de caminos se fue consolidando: mientras los anarquistas lograban hacerse fuertes en varios gremios influyentes - particularmente en el puerto y en los transportes-, impulsando la orientación favorable a la huelga general, los socialistas se replegaban sobre gremios de mayor calificación y desarrollaban una postura que insistía en la necesidad de impulsar huelgas parciales.

Esta divergencia de orientaciones no impidió, como vimos, que en 1901 ambas corrientes confluyeran en la conformación de la FOA, pero se trataba de un compromiso precario, en tanto unos y otros buscaban en la federación objetivos distintos. Mientras los anarquistas la veían como un paso necesario para dar impulso a la huelga general, los socialistas la consideraban una posible herramienta para evitarla. La coexistencia de ambas corrientes en la misma federación se hizo imposible y los socialistas advirtieron que no serian capaces de obtener una hegemonía: la constitución de diferentes sociedades por rama de actividad y finalmente la convocatoria a la huelga general en noviembre de 1902 pusieron de relieve hasta qué punto el anarquismo había recuperado terreno y ganado una influencia destacada en torno al cambio de siglo.

La huelga general y la fuerte represión que le siguió no hicieron más que reforzar estos planteamientos de los socialistas. "El Partido Socialista", decía La Vanguardia el 20 de diciembre de 1902, "necesitaba un acontecimiento trascendental que lo conmoviera intensamente, un acontecimiento que, poniendo a prueba su cohesión y disciplina, lo empujara una buena vez a tomar una actitud decisiva en el movimiento gremial argentino". La huelga general y la sanción de la Ley de Residencia eran así caracterizados como una bisagra en la historia del movimiento obrero local: lo ocurrido debía fortalecer al Partido Socialista "como organismo de opinión y de responsabilidad que es", capaz de "inspirar y dirigir la opinión obrera por las vías de la sensatez y la cordura, arrollando en su paso la descabellada propaganda que su encarnizado adversario el anarquismo ha ido destilando en el seno de nuestro proletariado".

La clase obrera argentina había sufrido un fuerte golpe, pero debía 
servir como lección. En efecto, si la influencia del anarquismo en amplias franjas de trabajadores era vista como una característica propia de un estadio temprano de desarrollo, lo ocurrido debía actuar como impulso para dar el salto hacia una etapa más avanzada, que era la que representaba el PS. Se reforzaba así la interpretación que veía al desarrollo de la conciencia y la organización obrera como un proceso gradual y no violento, en oposición a lo que se consideraba característico del planteamiento anarquista. "La obra de mejoramiento primero y de emancipación después", concluía La Vanguardia, "no se puede efectuar a saltos". Esto no implicaba dejar de intervenir en el movimiento gremial: antes bien, tenian planteada la tarea de "intervenir en las luchas gremiales, formar parte de las sociedades de resistencia, ilustrar con los conocimientos adquiridos el criterio de sus compañeros de explotación, a fin de realizar la obra que más dignifica por lo costosa: la obra de mejoramiento y redención de los humildes". ${ }^{29}$ En suma, la conclusión que sacaban los socialistas era un reforzamiento de sus planteos, contrarios a los estallidos huelguísticos y favorables a la tarea de organización y difusión gradual de sus ideas en las filas obreras.

\section{Bibliografia}

Abad de Santillán, Diego (1933), La FORA: ideología y trayectoria del movimiento obrero en la Argentina, Buenos Aires: Editorial Nervio.

Aricó, José (ed.) (1978), Debate sobre la huelga de masas, Cuadernos de Pasado y Presente 62, México: Siglo XXI.

Boido, Jorge Oscar (2002), "La primera huelga general en la República Argentina (1902). Sus características y significado, como expresión de la presencia de los obreros como clase en la lucha político económica", Tesis de Licenciatura, Universidad Nacional de Luján.

Bonamusa, Francesc (1991), “¿Reforma o revolución? 'La huelga de masas' en el primer debate socialista internacional (1893-1905)", Ayer, $\mathrm{n}^{\circ} 4$, Barcelona.

Colodrón, A. (1971), "Aproximación al estudio de la huelga general (la huelga general de Barcelona de 1902)", Revista de Trabajo, n 33, pp. 67-119.

Darraidou, Sebastián (2011), "Anarquistas y socialistas en el movimiento huelguístico en la Argentina de 1900 a 1902. Algunos problemas para su abordaje", Trabajadores, año 1, $\mathrm{n}^{\circ}$ 2. Buenos Aires, págs. 86-103.

Duarte, Ángel (1991), "Entre el mito y la realidad. Barcelona, 1902", Ayer, $\mathrm{n}^{\circ} 4$, Barcelona.

Engels, Friedrich (1873), "Los bakuninistas en acción". Ver online en

29. "Enseñanzas de los últimos sucesos", La Vanguardia, año IX, n 49, 20 de diciembre de 1902. 
Marxists Internet Archive: https://www.marxists.org/espanol/me/1870s/1873-bakun.htm

Falcón, Ricardo (2011), "Orígenes del movimiento socialista en Argentina. Prólogo. Capítulo I y II“. Cuadernos del Ciesal, año 8, nº 10, juliodiciembre, pp 11-45.

Hamon, A. (1896), El socialismo y el congreso de Londres, La Coruña: Imprenta El Progreso.

Haupt, Georges (1965), La deuxième internationale 1899-1914: étude critique des sources : essai bibliographique, Paris: Mouton.

Histoire de la Ile Internationale (1980a), vol. V, Ginebra, Minkoff.

Histoire de la IIe Internationale (1980b), vol. VI, Ginebra, Minkoff.

Joll, James (1966), The Second International, 1889-1914, Nueva York: Harper \& Row.

Korzeniewicz, Roberto (1989), “Labor Unrest in Argentina, 1887-1907”, Latin American Research Review, vol. 24, n 3.

Marotta, Sebastián (1960), El movimiento sindical argentino. Su génesis y desarrollo, 1857-1907, Buenos Aires: Editorial Lacio.

Oved, Iaacov (1978), El anarquismo y el movimiento obrero en Argentina. Buenos Aires: Siglo XXI.

Partido Socialista Argentino (1910), Movimiento socialista y obrero, Buenos Aires: La Vanguardia.

Poy, Lucas (2014), Los origenes de la clase obrera argentina. Huelgas, sociedades de resistencia y militancia politica en Buenos Aires, 1888-1896, Buenos Aires: Imago Mundi.

$* * *$

Titulo: The Socialist Party and strikes: an uneasy relationship.

An analysis of party positions in the early twentieth century

Resumen: El artículo analiza las posiciones del socialismo argentino respecto a la cuestión de las huelgas en el agitado período de conflictividad obrera que se extendió entre 1900 y 1902, trazando primero una recapitulación acerca del modo en que el tema había sido abordado en los años anteriores. Se muestra cómo el PS consolidó sus críticas respecto a la utilidad de las huelgas y, sobre todo, desenvolvió un cuestionamiento a la idea de huelga general, un tema que estaba siendo debatido en el movimiento socialdemócrata a nivel internacional. La hipótesis es que, si la huelga "grande" de 1896 contribuyó a que surgieran con firmeza las primeras posiciones contrarias a la generalización de las huelgas, la agitación de 1901-1902 inscribió en forma definitiva esta posición entre las líneas medulares de la interpelación del partido.

Palabras clave: Partido Socialista - huelga general - movimiento obrero - Segunda Internacional

Abstract: The paper addresses the political stance of Argentine Socialism regarding the question of strikes, during the turbulent years of labor unrest between 
1900 and 1902, after summarizing how the topic had been addressed in previous years. It shows how the Socialist Party consolidated a strong critique of the strikes' usefulness, and especially a durable opposition to the idea of general strikes, a question that was being discussed by the socialist movement globally. The articles argues that, if the big strike of 1896 contributed to the emergence of a strong criticism towards the idea of a general strike, the 1901-1902 wave of labor unrest definitely put this interpretation among the core political positions of the party.

Keywords: Socialist Party - general strike - labor movement - Second International

Recepción: 14 de agosto de 2014. Aprobación: 20 de diciembre de 2014. 